\title{
DIRETRIZES DE PROJETO DE ARTEFATOS TECNOLÓGICOS PARA MITIGAR CONFLITOS NA GESTÃO DO TEMPO NA PATERNIDADE
}

\author{
GUIDELINES FOR THE DESIGN OF TECHNOLOGICAL ARTIFACTS TO \\ MITIGATE CONFLICTS IN TIME MANAGEMENT IN FATHERHOOD
}

\author{
Daniel Mello Vidaletti ${ }^{1}$, M.Sc. \\ danielvidaletti@yahoo.com.br e http://orcid.org/0000-0001-6451-4113 \\ Leandro Miletto Tonetto ${ }^{1}$, D.Sc. \\ 1tonetto@unisinos.br e http://orcid.org/0000-0002-4403-2085 \\ Roberta Rech Mandelli ${ }^{1}$, M.Sc. \\ beta.mandelli@gmail.com e http://orcid.org/0000-0002-7306-2099 \\ Bruno Augusto Lorenz ${ }^{2}$, M.Sc. \\ lorenz.bruno@gmail.com e http://orcid.org/0000-0002-8693-145X
}

\author{
${ }^{1}$ Universidade do Vale do Rio dos Sinos (UNISINOS), Porto Alegre, Brasil \\ ${ }^{2}$ odd.studio, Porto Alegre, Brasil
}

experiência do usuário; design para emoção; concerns conflitantes; pai; filhos

Artefatos tecnológicos têm sido utilizados por muitos membros das famílias contemporâneas. Eles são conhecidos por seu potencial para promover a comunicação, reduzindo a distância percebida entre as pessoas. Nesse cenário, o tempo tem sido um problema para muitas famílias, o que inclui as figuras paternas. Os pais têm encontrado dificuldades para preencher seus papéis no desenvolvimento emocional das crianças. Esta pesquisa teve como objetivo gerar diretrizes para o design de artefatos tecnológicos para auxiliar na gestão de conflitos no tempo despendido pelo pai com seus filhos. O estudo adotou o conceito de concerns conflitantes (objetivos, atitudes e padrões aprendidos pelos pais no que se refere a suas relações com os filhos) para avaliar de que forma o design pode oferecer suporte a tais relações. Foram realizadas entrevistas com pais após um período de sensibilização. Elas foram analisadas por meio de Análise de Conteúdo. Com o suporte de um grupo composto por seis designers foram elaboradas 20 diretrizes de projeto com foco no pai, na relação tempo-espaço, nas relações sociais e afetivas, e nas atividades desenvolvidas pelos pais com seus filhos.

user experience; design for emotion; conflicting concerns; father; children

Technological artifacts have been in use by most members of contemporary families. They are known for their potential to promote communication, reducing the perceived distance between people. In such scenario, time has been an issue for many families, including father figures. They have struggled to fulfil their roles in the emotional development of their children. This research aimed to develop guidelines for the design of technological artifacts that may assist in the management of the time spent by fathers with their children. The study adopted the concept of conflicting concerns (goals, attitudes and patterns learned by fathers in regard to their relationships with their children) to assess how design could support such relationships. Interviews were conducted with fathers after a sensitization period in which they were asked to report and reflect on their time management. They were analyzed through Content Analysis. With the support of a group of six designers, 20 design guidelines were developed with a focus on the father, in the timespace relationship, in social and affective relationships, and in the activities developed by fathers with their children. 


\section{Introdução}

O papel do pai na educação infantil, em grande parte das sociedades, tem sido tradicionalmente definido como provedor de sustento da família; enquanto às mães é atribuída a função de cuidadora, tanto da parte emocional quanto educacional dos filhos (FREITAS, 2009). Este quadro tem sofrido alterações constantes nas últimas décadas devido às transformações sociais e ao aumento do número de mães no mercado de trabalho. Essas mudanças têm trazido discussões sobre os deveres do pai no cuidado com os filhos e, também, a respeito do compartilhamento das tarefas entre ambos os pais (BARCLAY e LUPTON, 1999).

Com isso, a interação mais intensa dos pais na criação de seus filhos traz novas definições a respeito das atribuições masculinas referentes à paternidade. Crouter, Bumpas, Head e McHale (2001) descrevem que uma das razões que pode afetar o envolvimento do papel do pai na relação com os filhos é a jornada de trabalho. As longas horas de trabalho diárias e a menor propensão à flexibilidade de horários ou licenças parentais podem ser classificadas como as principais razões para níveis mais baixos de envolvimento paterno, ocasionando estresse no equilíbrio entre trabalho e vida familiar. O excesso de trabalho faz com que o pai se sinta sobrecarregado e tenha tendência de menor qualidade de relacionamento com seus filhos. Além disso, a mãe acaba trazendo para si grande parte dos afazeres com os filhos, abrindo mão de carga horária de trabalho em prol do cônjuge (SILVA e OLIVEIRA, 2014).

No contexto familiar, a tecnologia tem permitido novas maneiras de gerar conexão entre os seus integrantes, através da interação pelo celular e por meio da internet. Kennedy, Smith, Wells e Wellam (2008) apontam que, apesar do receio de que a tecnologia pudesse separar as famílias, os casais têm usado seus telefones e a internet para manterem-se conectados, em especial quando possuem filhos, trazendo benefícios para a vida familiar. Com isso, muitos pais podem estar online com seus filhos mesmo com longas jornadas de trabalho, fazendo com que os telefones celulares e a internet sejam vistos como ferramentas positivas e com o intuito de melhorar as relações e a comunicação entre os membros da família.

Chaudron (2015) relata que as crianças entre 0 e 8 anos já estão inseridas no contexto tecnológico. O uso da tecnologia digital assumiu papel equilibrado no seu cotidiano, auxiliando com que acessem jogos, procurem programas ou músicas e pesquisem assuntos de seu interesse. Do mesmo modo, se faz útil como entretenimento para os filhos, enquanto os pais buscam tempo para si próprios. Dessa forma, muitos pais consideram as tecnologias digitais positivas, mesmo percebendo os riscos em relação ao tempo de exposição e à necessidade de regulação de conteúdos inapropriados para seus filhos. Os benefícios das atividades digitais relatados pelos pais no referido estudo foram aquisição de conhecimento e provisão educacional para necessidades futuras, coordenação motora e aprimoramento das habilidades de comunicação.

Por outro lado, apesar de todos os benefícios que as pessoas podem obter com o uso da tecnologia, Gergen e Gergen (2002) destacam que o uso excessivo das tecnologias digitais pode causar uma ruptura nas dinâmicas sociais, ocasionando o efeito da pessoa estar fisicamente presente, mas estar com a mente em um outro lugar durante o uso de telefones celulares.

Outro aspecto negativo do uso contínuo da tecnologia digital e móvel é definido por McDaniel (2015) pela expressão "technoference", ou seja, a interrupção cotidiana nas interações interpessoais, podendo ocorrer durante conversas ou atividades como refeições e brincadeiras. Apesar de existirem problemas relacionados ao uso excessivo de tecnologias digitais, Radesky, Schumacher e Zuckerman (2015) destacam que estas tecnologias, associadas aos smartphones, tablets e outros dispositivos móveis, estão incorporadas no cotidiano de crianças e de suas famílias. Sendo assim, a discussão aqui proposta é relacionada ao potencial uso positivo das tecnologias digitais para a qualificação das relações entre pais e filhos.

O design tem auxiliado na integração das necessidades humanas à tecnologia. Sua tradicional visão puramente tecnocêntrica vem se tornando menos sustentável, ao passo que novas estratégias que busquem 
trazer conceitos inovadores, para abordar os desafios globais de saúde, pobreza e educação, vem conferindo relevância ao design (BROWN, 2009).

Tonetto et al. (2020) destacam a contribuição do design para o estímulo e aprendizado de habilidades sociais em crianças. Mandelli e Tonetto (2019), por exemplo, apoiaram-se colaborativamente no design e na psicologia para gerar diretrizes de projeto de brinquedos com potencial de estimular a empatia, promovendo o desenvolvimento emocional das crianças.

Nas intersecções entre Psicologia e Design, uma das abordagens mais utilizadas é baseada na Teoria dos Appraisals, na qual são estudados os concerns do usuário, ou seja, suas atitudes, objetivos e padrões aprendidos na interação com artefatos (DESMET, 2002, 2007; DESMET e HEKKERT, 2007; TONETTO, 2012). É comum que existam conflitos internos em relação a diferentes concerns, tais como passar o tempo com os filhos ou dedicar-se a um esporte. Os concerns conflitantes apresentam como característica principal a necessidade de escolha entre duas opções divergentes e que não podem ser escolhidas simultaneamente (OZKARAMANLI, DESMET e ÖZCAN, 2017).

Foi estabelecido, como objetivo geral, compreender as possibilidades de redução ou eliminação de concerns conflitantes de gestão do tempo nas relações do pai com seus filhos por meio de artefatos tecnológicos. Foram propostos como objetivos específicos:

- Identificar os concerns conflitantes entre os pais e seus filhos na gestão do tempo;

- Compreender as características dos concerns no contexto do estudo que os tornam conflitantes para os pais;

- Avaliar a experiência atual dos pais com artefatos tecnológicos que potencialmente auxiliem na redução de concerns conflitantes em relação ao tempo;

- Compreender concerns conflitantes que não sejam, atualmente, mediados por artefatos tecnológicos (oportunidades de projeto);

- Desenvolver diretrizes de design de artefatos tecnológicos para auxiliar na mediação de conflitos na gestão da relação do tempo entre pais e filhos.

A seguir, são apresentados a fundamentação teórica (seção 2), o método da pesquisa (seção 3), resultados e discussão (seção 4), e considerações finais.

\section{Fundamentação teórica}

A revisão de literatura versa sobre os temas (i) design para emoção e concerns conflitantes e (ii) tecnologia nas relações familiares. O termo "usuário", advindo do design, refere a pessoa que usa as tecnologias projetadas e será adotado no presente manuscrito, a fim de manter a fidelidade ao conteúdo das referências utilizadas.

\subsection{Design e emoção}

O design emocional foi originado da união entre Psicologia e Design, na tentativa de compreender quais os processos emocionais envolvidos na atração dos usuários por determinado produto (TONETTO e COSTA, 2011). Desmet (2002) adotou a Teoria dos Appraisals (avaliações), identificando três variáveis para elaborar um modelo sobre emoções na interação homem-produto: (1) disposições para dada avaliação por meio de atitudes, objetivos e padrões dos usuários (concerns), (2) estímulos e (3) avaliação (appraisal).

Na literatura do Design, os tipos de concerns são descritos de forma ampla como "principais objetivos, motivos, bem-estar ou outras sensibilidades" do usuário (DESMET e HEKKERT, 2007, p.62, tradução nossa). A abrangência do conceito pode ser encontrada, em sua origem, na psicologia das emoções (FRIJDA, 
1986; LAZARUS, 1991). Nessa direção, as releituras da pesquisa em design apropriaram-se do conceito de formas variadas. A referida abertura a "outras sensibilidades" de Desmet e Hekker (2007) permite que se faça alterações no modelo teórico, que não é tratado de forma rígida mesmo na Psicologia.

Os concerns são as disposições, positivas ou negativas, de cada pessoa na interação com artefatos. A classificação mais comum dos tipos de concern, seguindo os autores de base (DESMET, 2002, 2007; DESMET e HEKKERT, 2007), divide-os em (i) atitudes, (ii) objetivos e (iii) padrões (DESMET, 2007). A mesma tipologia vem sendo adotada em estudos brasileiros sobre o tema (TONETTO, 2012). Neste estudo foram relacionadas as classificações dos concerns com a paternidade em: atitudes, como ter preferência por promover brincadeiras educativas, como jogos de memória, para os filhos; objetivos, como buscar maior interação com os filhos; e padrões, como acreditar que o homem deve prover financeiramente o sustento da família.

A característica principal dos concerns conflitantes, quando utilizados no design centrado no usuário, é a percepção da existência de duas opções de escolha pelo usuário que não podem ser exercidas simultaneamente. Concerns conflitantes são observados em situações em que um objetivo do indivíduo interfere em outro, dificultando que sejam conciliados (OZKARAMANLI e DESMET, 2012). A abordagem destes conflitos ocorre através de três principais constituintes: (i) as escolhas são mutuamente exclusivas no nível comportamental; (ii) as predisposições conflitantes estão ao nível cognitivo; e (iii) as emoções estão misturadas no nível afetivo (OZKARAMANLI, ÖZCAN e DESMET, 2017). Tais conflitos comumente são referentes a escolhas por desejos imediatos ao invés de objetivos de longo prazo (FISHBACH e ZHANG, 2008).

Ozkaramanli, Desmet e Özcan (2016) explicam que essas três categorias visam demonstrar outras formas de como o design pode abordar os concerns conflitantes dos usuários, do que apenas tentar resolvê-los, podendo ser formuladas declarações em diferentes níveis de abstração o que auxilia na direção de design a ser utilizada.

\subsection{Relações familiares e tecnologia}

A tecnologia vem assumindo papel cada vez mais relevante na vida familiar, tornando parte integrante também do cotidiano das crianças, de modo que elas podem facilmente utilizar dispositivos digitais em casa e na escola (SARACHO, 2015). Segundo Jackson (2011), tais dispositivos transformaram a maneira como as famílias agem nas suas rotinas e na forma como buscam entretenimento. Zevenbergen e Loan (2008) salientam que as crianças até os 6 anos de idade já estão imersas nas atividades promovidas pela tecnologia, exibindo competência e confiança no seu uso antes mesmo do início da idade escolar.

Esta invasão tecnológica no cotidiano da família foi denominada "technoference" por McDaniel e Coyne (2016), ou seja, interferências tecnológicas, intrusões ou interrupções diárias nas interações entre o casal, entre a família ou no tempo despendido juntos devido ao uso da tecnologia. Da mesma forma, em se tratando da relação à parentalidade, esta definição é utilizada para determinar a frequência com que a interferência da tecnologia pode afetar as atividades com a criança na hora de dormir, brincar, entre outras.

O uso da tecnologia pelos pais pode desempenhar muitos papéis nas relações familiares, como o uso de sites, redes sociais e blogs utilizados para se conectarem com a família, aumentando o apoio entre eles e a satisfação no relacionamento (MCDANIEL, COYNE e HOLMES, 2012). De maneira positiva, a tecnologia pode ser utilizada pela família para reforçar os relacionamentos durante o tempo compartilhado, como o tempo despendido assistindo televisão ou jogando videogames em família pode ser associado a um maior sentimento de conexão entre os integrantes (PADILLA-WALKER, COYNE e FRASER, 2012). Por outro lado, aparelhos eletrônicos também podem ser responsáveis por frequentes interrupções nas interações do dia-a-dia (OULASVIRTA et al., 2012). 
O estudo realizado por Wellman, Smith, Wells e Kennedy (2008) aponta que as famílias com crianças interagem com mais regularidade do que as famílias que não possuem filhos, o que ocorre devido à maior probabilidade do uso da internet, dispositivos móveis e computadores, o que requer que os pais precisem se atualizar constantemente para auxiliar as crianças. Dessa forma, cabe aos pais determinar as regras de utilização e de acesso às tecnologias e, também, atuarem como instrutores para as dificuldades que possam surgir durante a interação com os dispositivos tecnológicos (GENC, 2014).

Um uso muito apropriado que pode ser promovido pela tecnologia é a interação entre pais, filhos e professores. Segundo Olmstead (2013), o uso da tecnologia para manter os pais conectados com a escola traz um envolvimento mais proativo dos pais nas atividades e atualizações diárias dos filhos. Da mesma forma, a escola pode informar os pais a respeito de professores, eventos, atualizações e acontecimentos da sala de aula. Uma outra forma de utilização proativa da tecnologia é no auxílio às crianças com as lições de casa, através da disponibilização online de livros didáticos. Assim, tanto pais quanto professores compreendem como de alto valor o uso de meios tecnológicos para promover um maior envolvimento nas atividades diárias da criança com os pais e com a escola.

Dias e Brito (2016) descrevem que os pais consideram as tecnologias fundamentais para garantir melhores condições futuras para os filhos. Dessa forma, os dispositivos digitais podem ser vistos como facilitadores do aprendizado e da rotina diária, tornando as atividades mais ágeis e fáceis de serem executadas. No entanto, os pais se sentem nostálgicos em relação a sua própria infância longe das tecnologias digitais e gostariam que seus filhos pudessem experimentar mais atividades e brincadeiras ao ar livre, interagindo com outras crianças. Ao mesmo tempo, a liberdade oferecida pela tecnologia, como o rápido acesso à informação, pode auxiliar as crianças a se transformarem em ser humanos mais conscientes do mundo em que estão inseridas. Assim, apesar de a tecnologia oferecer benefícios na rotina da família, os pais também estão preocupados com a dependência de seus filhos ao preferirem ficar em casa, ao invés de desenvolverem atividades ao ar livre e com outras crianças.

Embora se possa compreender estes dilemas vivenciados pelas famílias em relação à utilização da tecnologia, esta pesquisa se propôs a avaliar os potenciais benefícios que a tecnologia pode gerar para auxiliar o pai a melhorar seu relacionamento com os filhos. Dessa forma, acredita-se que projetos de design orientados para o bem-estar do pai, dos filhos e da família através do uso da tecnologia, auxiliando na gestão do seu tempo, podem intensificar as relações familiares e ampliar a participação do pai.

\section{Método de pesquisa}

A pesquisa foi avaliada e aprovada em termos éticos por meio da Plataforma Brasil (processo número CAAE: 94922818.2.0000.5344). Ela adotou o método qualitativo exploratório em Design, baseado em entrevistas em profundidade, descrito nas subseções a seguir (TONETTO, RENCK e STEIN, 2014).

\subsection{Procedimentos e instrumento de coleta de dados}

Os participantes foram recrutados por conveniência, por meio da rede de contatos dos pesquisadores. Foram recrutados homens adultos, casados ou solteiros, que desempenham atividades laborais e que têm filhos em idade pré-escolar, entre 2 e 5 anos. O critério para a definição de faixa etária dos filhos considerou que, nessa idade, as crianças já estabelecem comunicação verbal com os pais, mas ainda são bastante dependentes de cuidados maternos e paternos. Além disso, as crianças após os 6 anos comumente iniciam o ensino fundamental, o que potencialmente modifica suas relações familiares.

No momento do recrutamento, os objetivos da pesquisa foram explicados a cada entrevistado. Mediante aceite preliminar para participar da pesquisa, eles foram convidados a ler, tirar suas dúvidas e assinar um Termo de Consentimento Livre e Esclarecido (TCLE). 
Em período anterior às entrevistas em profundidade, foi realizado um período de sensibilização de sete dias sobre o tema. Demir et al. (2009) explicam que o principal objetivo da etapa de sensibilização é gerar uma introspecção emocional nos participantes através do relato diário das experiências emocionais ocorridas, preparando-os para a fase da entrevista em profundidade. Ele ocorreu da seguinte forma: os participantes receberam mensagens pelo aplicativo WhatsApp, pedindo que respondessem com uma mensagem de áudio se viveram algum conflito na gestão do tempo com os filhos nas últimas $24 \mathrm{~h}$, descrevendo sua natureza e motivo. Este procedimento ocorreu diariamente ao longo dos sete dias.

Após os sete dias, os pais concederam a entrevista, agendada em horários e locais de acordo com suas disponibilidades, na qual os conflitos indicados nas mensagens de áudio foram explorados. Foram identificados, ainda, artefatos digitais que tenham auxiliado na mediação desses conflitos, possibilitando a avaliação de oportunidades de projeto, a partir de conflitos não mediados por artefatos. As entrevistas foram áudio-gravadas e posteriormente transcritas.

\subsection{Participantes}

Foram entrevistados 10 pais. A delimitação do número de participantes se deu pelo fechamento amostral por saturação. Suas características podem ser observadas no Quadro 1.

\begin{tabular}{|c|c|c|c|c|c|}
\hline Nome fictício & Idade & Estado civil & Formação & Ocupação & Número de filhos \\
\hline Pedro & 37 anos & União Estável & Educação Física & Professor & 1 filho de 2 anos \\
\hline José & 34 anos & Casado & Administração & Empresário & 1 filha de 3 anos \\
\hline Mateus & 37 anos & Casado & Administração & Gerente de Projetos & $\begin{array}{l}2 \text { filhas, uma de } 4 \\
\text { anos e uma de } 2 \text { anos }\end{array}$ \\
\hline Felipe & 47 anos & Casado & Engenheiro Eletricista & $\begin{array}{l}\text { Engenheiro de Sistemas } \\
\text { Aviônicos }\end{array}$ & $\begin{array}{l}2 \text { filhos, um de } 5 \text { anos } \\
\text { e um de } 3 \text { anos }\end{array}$ \\
\hline Paulo & 34 anos & União Estável & $\begin{array}{l}\text { Sistemas de } \\
\text { Informação }\end{array}$ & Analista de infraestrutura & 1 filho de 3 anos \\
\hline João & 40 anos & Casado & Jornalista & Pesquisador & 1 filho de 4 anos \\
\hline Gabriel & 35 anos & União Estável & Superior incompleto & Supervisor Técnico & 1 filho de 3 anos \\
\hline Francisco & 26 anos & União Estável & Superior incompleto & Auxiliar de manutenção & 1 filha de 5 anos \\
\hline Davi & 30 anos & União Estável & Técnico de Edificações & Supervisor Técnico & 1 filho de 2 anos \\
\hline Tiago & 41 anos & União Estável & Educação Física & Motorista de Aplicativos & 1 filho de 5 anos \\
\hline
\end{tabular}

Tabela 1: Apresentação dos pais participantes

\subsection{Procedimentos para análise de informações}

Os dados foram analisados por meio da Análise de Conteúdo (Bardin, 2006). As entrevistas foram transcritas, e as verbalizações referentes a conflitos entre concerns foram destacadas com base na transcrição dos áudios das entrevistas e agrupadas por similaridade, o que gerou as categorias de análise.

Assim, as categorias de análise foram elaboradas a posteriori, ou seja, emergiram do discurso dos próprios entrevistados. No entanto, o processo de análise também foi baseado no modelo descrito por Desmet (2002, 2007) e Desmet e Hekkert (2007), categorizando os concerns em atitudes, objetivos e padrões. O framework foi utilizado para categorizar os diferentes tipos de concerns e suas potenciais relações com artefatos tecnológicos (DESMET, 2007).

Através da análise das entrevistas em profundidade, foram identificados os concerns conflitantes dos pais. Os resultados foram catalogados em uma planilha de dados. Este procedimento ocorreu para que as informações pudessem ser organizadas de modo a se identificar o padrão de comportamento dos conflitos vivenciados pelos entrevistados. Durante esta catalogação, as falas dos pais foram classificadas como (i) conflitos que possuem relação com tecnologia, (ii) conflitos que não possuem relação com tecnologia e (iii) conflitos que poderiam ser solucionados com o apoio de algum artefato tecnológico. Esta categorização serviu como auxílio para a compreensão de conflitos do pai e, também, na identificação de oportunidades de 
projetos com base em situações nas quais não havia intervenção de artefatos tecnológicos para a mediação de conflitos. Foram identificados seis grupos de concerns.

Para a definição das diretrizes de design foi proposta uma triangulação através da discussão com um grupo de designers e profissionais de tecnologia da informação (TI). O procedimento foi semelhante à realização de um grupo focal, mas o foco foi a interpretação dos resultados e não a produção de conteúdo sobre os conflitos. O objetivo foi propor, com base nas categorias de análise, diretrizes para que futuros designers possam se basear ao projetarem produtos/serviços tecnológicos com foco na melhora da gestão do tempo do pai na relação com seus filhos. O Quadro 2 apresenta as características dos seis participantes.

\begin{tabular}{l|l|l|l}
\hline Participante & \multicolumn{1}{|c|}{ Idade } & \multicolumn{1}{c|}{ Formação } & \multicolumn{1}{c}{ Profissão } \\
\hline Designer 1 & 26 anos & Graduação em Design e Mestrado em Design & Designer Estratégico \\
\hline Designer 2 & 29 anos & Graduação e Mestrado em Design & Professor Universitário \\
\hline Designer 3 & 37 anos & Graduação em Comunicação Social & Designer UX/UI \\
\hline Designer 4 & 36 anos & $\begin{array}{l}\text { Graduação em Design Gráfico e Pós-graduação em User } \\
\text { Experience }\end{array}$ & Designer na área de TI \\
\hline Designer 5 & 29 anos & Graduação em Produção Multimídia e Mestrado em Design & Designer Gráfico e Marketing Digital \\
\hline Designer 6 & 35 anos & $\begin{array}{l}\text { Graduação em Comunicação Social e Pós-graduação em } \\
\text { Design Centrado no Usuário }\end{array}$ & $\begin{array}{l}\text { Product Designer / UX Designer na } \\
\text { área de TI }\end{array}$ \\
\hline
\end{tabular}

Quadro 2 - Perfil dos participantes

Foram elaborados seis cards para facilitar a apresentação das categorias (concerns conflitantes) aos profissionais, contendo a identificação de cada conflito e falas que os exemplificam. A questão-guia apresentada foi a seguinte: "O que diríamos aos profissionais de design que trabalham no desenvolvimento de produtos tecnológicos, sobre o que eles deviam ter atenção para aproximar pais e filhos?". Após a apresentação dos cards e do esclarecimento de dúvidas, os integrantes do grupo compartilharam suas ideias com os demais, que eram estimulados a discutir sua pertinência como diretriz de design. Por fim, após o debate de cada possível diretriz entre o grupo, cada participante deveria mostrar as cartas que julgava relacionadas a ela. Dessa forma, foi possível identificar os conflitos relacionados a cada uma.

A seção seguir descreve as categorias de concerns conflitantes do pai no relacionamento com os seus filhos, bem como as diretrizes de design propostas para auxiliar na resolução/redução destes conflitos.

\section{Análise de resultados}

Apresenta-se, inicialmente, os resultados da Análise de Conteúdo das entrevistas com os pais (4.1). Em seguida (4.2), as diretrizes de design são discutidas.

\subsection{Análise de conteúdo}

Para auxiliar no compreendimento dos concerns, Desmet (2007) distinguiu-os em três categorias: atitudes, objetivos e padrões. Quando estas categorias são associadas ao papel do pai, elas podem ser compreendidas como:

(a) As atitudes são as predisposições que permitem o pai se aproximar ou se afastar de objetos, outras pessoas ou eventos. As atitudes dos pais dizem respeito ao modo como suas predisposições estão direcionadas para participar ativamente da vida dos filhos e, da responsabilidade frente ao fato de ter que trabalhar e estudar, equilibrando a sua vida pessoal com a paternidade.

(b) Os objetivos podem ser compreendidos como os elementos que o pai deseja alcançar. Neste contexto, a decisão pela priorização do trabalho, a necessidade de se desenvolver na criação dos filhos e, ascender profissionalmente na carreira são objetivos comuns enfrentados pelos pais.

(c) Os padrões estão relacionados às crenças, convenções ou normas referentes ao modo como se acredita que o pai deveria se comportar em relação ao que foi aprendido e ao que a sociedade espera 
de sua postura, como a importância da relação entre ser provedor financeiro e preocupação da sua presença com os filhos.

Partindo-se da compreensão dos concerns apresentada por Desmet (2007), foram identificadas seis categorias de concerns conflitantes na análise de conteúdo. No Quadro 3, elas são relacionadas ao tipo de concern (atitudes, objetivos e padrões). Como cada categoria envolve duas dimensões conflitantes, elas foram geralmente relacionadas a dois tipos de concern.

\begin{tabular}{|c|c|c|c|}
\hline Concerns Conflitantes X Tipos de Concerns & Atitudes & Objetivos & Padrões \\
\hline $\begin{array}{l}\text { Eu gostaria de acompanhar o dia-a-dia da criança (atitude), mas preciso priorizar o trabalho hoje } \\
\text { (objetivo). }\end{array}$ & $\bar{X}$ & $\mathbf{X}$ & \\
\hline $\begin{array}{l}\text { Eu quero ter uma boa autoimagem como pai (objetivo), mas preciso priorizar o trabalho hoje } \\
\text { (objetivo). }\end{array}$ & & $\mathbf{X}$ & \\
\hline $\begin{array}{l}\text { Eu gostaria/devo de ser um pai presente nas atividades lúdicas da criança (atitude ou padrão), } \\
\text { mas preciso priorizar o trabalho hoje (objetivo). }\end{array}$ & $\mathbf{X}$ & $\mathbf{X}$ & $\mathbf{X}$ \\
\hline $\begin{array}{l}\text { Eu devo cumprir as responsabilidades como pai (padrão), mas quero desenvolver atividades de } \\
\text { interesse pessoal (objetivo). }\end{array}$ & & $\mathbf{X}$ & $\mathbf{X}$ \\
\hline $\begin{array}{l}\text { Eu preciso me desenvolver profissionalmente no longo prazo (objetivo), mas gostaria de } \\
\text { acompanhar o dia-a-dia da criança (atitude). }\end{array}$ & $\mathbf{X}$ & $\mathbf{X}$ & \\
\hline $\begin{array}{l}\text { Eu acredito que devo ser provedor (padrão), mas também penso que deveria ser presente } \\
\text { (padrão). }\end{array}$ & & & $\mathbf{X}$ \\
\hline
\end{tabular}

Quadro 3 - Categoria de Concerns Conflitantes dos pais

\subsubsection{Eu gostaria de acompanhar o dia-a-dia da criança (atitude), mas preciso priorizar o trabalho hoje (objetivo)}

A primeira categoria de concerns conflitantes trata da administração do tempo do pai utilizado para a convivência com os filhos. Apesar dos avanços sociais, a menor propensão à flexibilidade de horários pode ser classificada como a principal razão para níveis mais baixos de envolvimento paterno, ocasionando estresse no equilíbrio entre trabalho e vida familiar, principalmente quando se trata de culturas e contextos mais patriarcais. (CROUTER et al., 2001). Um dos pais entrevistados relatou:

O que acontece é que o nosso trabalho às vezes nos toma muito tempo e o que eu procuro fazer, que eu estava dizendo, é tentar o máximo possível fazer as minhas tarefas do trabalho o quanto antes e tentar estar com o meu filho o máximo possível de tempo. Como ele tem uma rotina muito agitada, vamos dizer, durante a semana, então a gente consegue ficar com ele mais tempo. (Gabriel).

Conciliar o trabalho remunerado, a vida familiar e os compromissos exigem do pai um equilíbrio muitas vezes difícil de se manter como rotina. Comumente o trabalho acaba sendo priorizado. Covey (2007) afirma que a organização do tempo, quando transformada em tarefas e compromissos, visa alcançar os objetivos e resultados esperados pelo indivíduo, exigindo uma avaliação individual de como o tempo é ocupado. $\mathrm{O}$ autor recomenda que as tarefas e compromissos estejam voltados, primeiramente, para os mais importantes, reduzindo desperdício ou má utilização do tempo. (COVEY, 2007).

\subsubsection{Eu quero ter uma boa autoimagem como pai (objetivo), mas preciso priorizar o trabalho hoje (objetivo)}

Assim como no concern conflitante anterior, nesta categoria existe também o conflito a respeito da priorização do trabalho, porém, neste caso, concorrendo com a autocrítica que os entrevistados fizeram em relação a suas habilidades paternas. Para muitos pais, o tempo que se pode despender com os filhos é um medidor da qualidade do cuidado, sendo os appraisals o balanço que se estabelece entre trabalho-família e os recursos de trabalho e rede familiar suficientes. A sensação de falta de tempo com as crianças pode levar a sentimentos negativos e insatisfação com a vida familiar (MILKIE et al., 2010). Assim, esta categoria pode ser demonstrada através da fala de Felipe: "Eu acho que é mais um conflito emocional, porque tu chegas em casa eles já tão 
dormindo. Não tem contato com eles basicamente. Só chega lá e dá um beijinho na testa, boa noite e era isso.” (Felipe).

A preocupação com a autoimagem como pai levanta dúvidas em relação ao uso do tempo em outras atividades. Nessa direção, Milkie et al. (2004) apontam a necessidade de ter mais tempo para/com os fillhos como o maior desafio enfrentado pelos pais, muitas vezes obrigando-os a adotar estratégias que favoreçam o equilíbrio da vida familiar.

\subsubsection{Eu gostaria/devo ser um pai presente nas atividades lúdicas da criança (atitude ou padrão), mas preciso priorizar o trabalho hoje (objetivo)}

Nesta categoria, o conflito relatado foi entre o trabalho e as atividades de lazer com os filhos. Estar presente em atividades lúdicas pode ser compreendido como um padrão de comportamento aprendido e, ao mesmo tempo, como uma predisposição do pai (atitude). A fala de Paulo ilustra esta categoria:

Eu gosto todos os dias, nem que seja antes de sair ou depois de chegar em casa, ter um tempo pra brincar com ele (...). E naquele dia eu acabei saindo tarde daqui [do trabalho], cheguei tarde, ele estava dormindo. Eu me sinto culpado por não ter cumprido esse ritual de ter visto ele, de ter ficado com ele. Por mais que ele esteja com sono, ranzinza, eu prefiro estar com ele assim, do que não ter visto ele durante o dia. (Paulo).

O envolvimento do pai de forma efetiva no dia-a-dia dos filhos leva a uma maior autoconfiança e a uma paternidade mais satisfatória, pois os pais se sentem mais importantes para os filhos (ALLEN e DALY, 2007). O sentimento de culpa pôde ser identificado em várias entrevistas, assim como a necessidade de estratégias de compensação pelo tempo perdido.

\subsubsection{Eu devo cumprir as responsabilidades como pai (padrão), mas quero desenvolver atividades de interesse pessoal (objetivo)}

Os conflitos percebidos nesta categoria são entre a responsabilidade de atuar no papel de pai e a vontade de desenvolver atividades que não estão relacionadas aos filhos. A sociedade e as crenças do próprio homem podem exercer pressão para que o pai assuma a responsabilidade pelos filhos. Assim, este concern pode conflitar com os desejos do indivíduo em realizar outras atividades, como lazer, esportes, hobbies, entre outros. A fala de Felipe traz essa situação em uma descrição de rotina de cuidados físicos: "Eu uso meu horário de almoço, três vezes por semana, para fazer a minha academia. De noite não tem como. É difícil. Só que às vezes acontece uma coisa que outra, daí já deixei de fazer academia e saí para comprar as coisas da escola para meu filho." (Felipe).

A conciliação entre o trabalho remunerado, a vida familiar e os demais compromissos exige do pai um equilíbrio que frequentemente se torna difícil de manter no dia-a-dia. Assim, uma das percepções do pai que demonstra o desequilíbrio desta equação é a sensação de falta de tempo suficiente com as crianças (MILKIE et al., 2010).

\subsubsection{Eu preciso me desenvolver profissionalmente no longo prazo (objetivo), mas gostaria de acompanhar o dia-a-dia da criança (atitude)}

A paternidade pode transformar os homens, fazendo com que suas prioridades sejam constantemente reavaliadas de acordo com as necessidades dos filhos. Este efeito faz com que se tornem mais sensíveis com os filhos, alterando suas atividades sociais de modo a investir mais tempo nas atividades altruístas (EGGEBEEN, DEW e KNOESTER, 2010). Por outro lado, Keeney et al. (2013) afirmam que a razão mais comum para que pais busquem a educação continuada é o crescimento na carreira, ocasionando frustração 
quando uma oportunidade de ascensão é perdida pela falta de tempo para investir em qualificação. A fala de Davi durante ilustra esta situação:

Estou buscando um desenvolvimento, crescimento profissional e acaba tendo um pouco de impacto nos compromissos do dia-a-dia com o meu filho, mas eu tenho buscado ter esse cuidado. Consigo identificar isso, quando eu vejo que estou ausente, para eu me policiar e dar mais atenção pra ele. (Davi).

O concern categorizado como objetivo, que trata do desenvolvimento profissional, tem relação direta com a meta que o pai almeja para a sua profissão. Por outro lado, o concern de atitude, alusivo ao acompanhamento do dia-a-dia do filho, faz referência às predisposições afetivas que a paternidade desenvolve no homem. Almeida, Wethington e Mcdonald (2001) afirmam que, quanto mais tempo os pais passam com os filhos, mais propensos estarão de participarem de interações tanto emocionalmente favoráveis, como conflitantes.

\subsubsection{Eu acredito que devo ser provedor (padrão), mas também penso que deveria ser presente (padrão)}

O comportamento do pai é influenciado significativamente por crenças e práticas intergeracionais das famílias de origem (KANE, GADSDEN e ARMORER, 1997). Padrões como a responsabilidade financeira e a presença paterna atuam como crenças aprendidas pelo pai ao longo de sua vida ou à normas criadas pela sociedade $\mathrm{e}$, assim, quando colocadas em contraposição ocasionam o concern conflitante do pai representado nesta categoria. No depoimento abaixo de Francisco pode ser evidenciada esta categoria de concern conflitante: "Graças a Deus, consegui contribuir com questões financeiras e tal. Nunca faltou nada, estuda na escolinha que a gente pretendia colocar ela, porque também acho muito importante. A gente hoje não tem o convívio diário, passa mais tempo na empresa do que em casa." (Francisco).

Embora possam existir receios de que a tecnologia possa dispersar a família, Wellman et al. (2008) identificaram que é comum os casais utilizarem smartphones para coordenarem suas vidas, especialmente quando possuem filhos, facilitando o acompanhamento do dia-a-dia das crianças. As famílias que possuem filhos são mais conectadas que as que não os têm, e os pais precisam de atualização constante para acompanhar as crianças na utilização dos dispositivos tecnológicos.

\subsection{Diretrizes de design}

Através da discussão de resultados com os designers, foram propostas 20 diretrizes de projeto de artefatos tecnológicos que atendessem uma ou mais das seis categorias de concerns identificadas. Foram formulados quatro agrupamentos de diretrizes de design:

1) Foco no pai: visam oferecer direcionamentos que embasem os projetos de design de artefatos tecnológicos com benefícios diretos para a figura paterna e para o desenvolvimento da sua competência como genitor.

2) Relação tempo-espaço: buscam facilitar a relação do pai e seus filhos em termos da distância, muitas vezes promovidas pelo trabalho do pai. Da mesma forma, neste grupo são tratadas as questões do tempo do pai, seja em razão do seu melhor aproveitamento, da qualidade do tempo despendido na relação pai-filho e da limitação do tempo devido às atividades do dia-a-dia do pai.

3) Relações sociais e afetivas: objetivam a promoção de melhores relacionamentos entre o pai e a criança, tanto de maneira afetiva, quanto na sociedade.

4) Atividades em conjunto: oferecem diretrizes para a produção de inovações nas atividades de interação entre o pai e os filhos, buscando proporcionar novas formas de entretenimento e lazer, oferecendo opções que incentivem o lado lúdico necessário na paternidade. 
As diretrizes identificadas e os seus agrupamentos podem ser observadas no Quadro 4.

\begin{tabular}{|c|c|c|}
\hline Agrupamento & Diretrizes de Design & Concerns \\
\hline \multirow[t]{8}{*}{ Foco no pai } & $\begin{array}{l}\text { Promover maior aproximação, conhecimento e confiança do pai em relação a cuidadores da } \\
\text { criança (ex.: Facilitar a comunicação com babás e escolinhas) }\end{array}$ & $1|2| 3 \mid 5$ \\
\hline & Promover educação sobre o desenvolvimento infantil & $1|2| 3|4| 5 \mid 6$ \\
\hline & $\begin{array}{l}\text { Não reforçar o controle pelo pai (ex.: Não incluir dispositivos que possibilitem o controle } \\
\text { excessivo das crianças através de câmeras) }\end{array}$ & $1|2| 3 \mid 5$ \\
\hline & $\begin{array}{l}\text { Promover a reflexão sobre o papel paterno (ex.: incluir nos artefatos tecnológicos dispositivos } \\
\text { regulados pelo pai que permitam visualizar suas responsabilidades) }\end{array}$ & $2|3| 6$ \\
\hline & \begin{tabular}{|l} 
Fomentar a autoaceitação como pai (ex.: além das responsabilidades supracitadas, \\
considerar incluir lembretes de atividades pessoais a serem conciliadas com as familiares)
\end{tabular} & $2 \mid 3$ \\
\hline & $\begin{array}{l}\text { Propor o questionamento do papel do pai (ex.: possibilitar a autoavaliação sistemática de } \\
\text { sua dedicação e desempenho nas atividades com a criança) }\end{array}$ & $2 \mid 6$ \\
\hline & $\begin{array}{l}\text { Promover a aceitação do filho como ele é (ex.: evitar dispositivos que favorecem uma } \\
\text { imagem positiva idealizada da criança e do relacionamento) }\end{array}$ & $2 \mid 3$ \\
\hline & $\begin{array}{l}\text { Considerar e reforçar memórias e lembranças positivas do pai e da criança (ex.: registros de } \\
\text { imagens afetivas) }\end{array}$ & $2|4| 5$ \\
\hline \multirow[t]{6}{*}{$\begin{array}{l}\text { Relação tempo- } \\
\text { espaço }\end{array}$} & $\begin{array}{l}\text { Facilitar o trabalho remoto (home office), quando o domicílio favorece proximidade com a } \\
\text { família e distanciamento físico para o trabalho }\end{array}$ & $1|2| 3|5| 6$ \\
\hline & $\begin{array}{l}\text { Focar na redução da percepção de distância entre o pai e a criança (ex.: facilitar pequenas } \\
\text { interações não disruptivas ao longo do dia) }\end{array}$ & $1|2| 3 \mid 6$ \\
\hline & $\begin{array}{l}\text { Fomentar o exercício de foco no agora (ex.: promover a atenção total do pai na interação } \\
\text { com o filho, destacando o impacto e a relevância de cada atividade para o desenvolvimento } \\
\text { da criança) }\end{array}$ & $1|2| 3|4| 5 \mid 6$ \\
\hline & $\begin{array}{l}\text { Considerar a limitação do tempo disponível (ex.: possibilitar customização nas atividades } \\
\text { que refletem o papel paterno indicadas no bloco anterior de diretrizes, facilitando uma } \\
\text { imagem realista sobre a paternidade) }\end{array}$ & 3 \\
\hline & $\begin{array}{l}\text { Diminuir interferências externas no tempo em que pai e filho estiverem juntos (ex.: possibilitar } \\
\text { controle customizado sobre notificações mobile por ocasião) }\end{array}$ & 3 \\
\hline & $\begin{array}{l}\text { Promover a otimização do tempo do pai (ex.: aplicativo que "calcule rotas", em alusão a } \\
\text { aplicações de mapas, para otimização de atividades similares) }\end{array}$ & 5 \\
\hline \multirow[t]{5}{*}{$\begin{array}{l}\text { Relações sociais } \\
\text { e afetivas }\end{array}$} & $\begin{array}{l}\text { Buscar a inclusão da criança em uma diversidade de ambientes nos quais o pai está } \\
\text { inserido, aproximando-os no cotidiano }\end{array}$ & $|1| 3|4| 5$ \\
\hline & $\begin{array}{l}\text { Incentivar a expressão de amor e o carinho paterno (ex.: disponibilizar recordações de } \\
\text { momentos positivos por imagens de eventos passados) }\end{array}$ & $2|3| 6$ \\
\hline & $\begin{array}{l}\text { Incluir a figura paterna nas representações/comunicações midiáticas da função de cuidar } \\
\text { (ex.: imagens em comunicação digital) }\end{array}$ & 6 \\
\hline & $\begin{array}{l}\text { Fomentar o compartilhamento das atividades relacionadas à criança entre o pai e a mãe, } \\
\text { estimulando a divisão de tarefas (ex.: agendas compartilhadas) }\end{array}$ & $4 \mid 6$ \\
\hline & $\begin{array}{l}\text { Proporcionar atividades que oportunizem o lazer compartilhado entre o pai e os filhos (ex.: } \\
\text { atividades colaborativas) }\end{array}$ & $1|2| 3 \mid 4$ \\
\hline $\begin{array}{l}\text { Atividades em } \\
\text { conjunto }\end{array}$ & $\begin{array}{l}\text { Focar mais no processo que no resultado de atividades compartilhadas (ex.: evitar atividades } \\
\text { e jogos meramente competitivos) }\end{array}$ & 3 \\
\hline
\end{tabular}

\section{Quadro 4 - Diretrizes de Design}

Legenda: Categorias de concerns - (1) Eu gostaria de acompanhar o dia-a-dia da criança (atitude), mas preciso priorizar o trabalho hoje (objetivo). (2) Eu quero ter uma boa autoimagem como pai (objetivo), mas preciso priorizar o trabalho hoje (objetivo). (3) Eu gostaria/devo de ser um pai presente nas atividades lúdicas da criança (atitude ou padrão), mas preciso priorizar o trabalho hoje (objetivo). (4) Eu devo cumprir as responsabilidades como pai (padrão), mas quero desenvolver atividades de interesse pessoal (objetivo). (5) Eu preciso me desenvolver profissionalmente no longo prazo (objetivo), mas gostaria de acompanhar o dia-a-dia da criança (atitude). (6) Eu acredito que devo ser provedor (padrão), mas também penso que deveria ser presente (padrão). Fonte: Elaborado pelos autores (2020).

\section{Considerações finais}

Este artigo teve por objetivo compreender e traçar diretrizes para redução ou eliminação dos concerns conflitantes na gestão do tempo do pai, de modo a oferecer melhores relações com seus filhos por meio de 
artefatos tecnológicos. Foram observadas seis categorias de concerns conflitantes do pai por meio das entrevistas em profundidade, as quais geraram 20 diretrizes de projeto de artefatos tecnológicos.

Cabe ressaltar que alguns dos conflitos percebidos pelo pai em relação aos filhos não deveriam ser reduzidos ou amenizados. Os conflitos do pai em razão da sua necessidade de estar presente nas atividades dos filhos, ter que trabalhar, se desenvolver profissionalmente, gerar proventos para a família, entre outros, existem e fazem parte do papel paterno, dos desafios em ser pai e em ter que conciliar todas as atividades envolvidas. Nesta direção, é papel do designer avaliar as diretrizes com cuidado ao propor novos projetos, a fim de não estimular redução de conflitos que deveriam existir. Sugere-se, portanto, prudência no uso das diretrizes, já que mitigar conflitos que tenham potencial negativo na educação da criança, do ponto de vista social e emocional, não é recomendado do ponto de vista ético.

Embora compreenda-se os pontos negativos relatados a respeito do uso de tecnologias digitais pelos pais, torna-se imprescindível questionar: Seria esta uma oportunidade para propor artefatos com potencial transformador de hábitos potencialmente negativos? Seria viável proporcionar melhores experiências ao pai na sua conduta como criador e educador, visando ampliar seu conhecimento a respeito de suas limitações e dificuldades? Através desta pesquisa pretende-se que o olhar do designer se torne mais crítico em relação aos efeitos da tecnologia nas relações familiares e, em especial nas necessidades particulares do pai, tornando os projetos de design que envolvam a tecnologia digital mais assertivos, baseando-se nos concerns conflitantes apontados nesta pesquisa.

Este trabalho também objetivou, do ponto de vista acadêmico, ampliar o conhecimento a respeito dos concerns conflitantes, visto que se trata de um campo recente de atuação do design, auxiliando no desenvolvimento de ferramentas para pesquisas centradas no usuário. Neste caso, focada nas relações entre pai e filhos, a introdução destas novas diretrizes de design pode contribuir para o embasamento teórico para futuras pesquisas e estratégias de design que visem atuar na melhora da qualidade de vida do pai, das suas crianças e da sua família.

As diretrizes identificadas neste estudo criam subsídios de base para que os designers, de posse desse novo conhecimento, possam projetar para auxiliar na interação e na melhoria da qualidade das relações entre pai e filhos, possibilitando uma melhor gestão do tempo em família. Pesquisas e projetos que permitam a aplicação das diretrizes traçadas na pesquisa têm o potencial para reforçar o caráter de inovação social do Design.

Nessa direção, os concerns conflitantes, dilemas, estão relacionados à tomada de decisões que ocorrem diariamente na vida das pessoas. Os produtos, serviços e ambientes desenvolvidos a partir da identificação destas necessidades desempenham papel importante tanto para os seus usuários, quanto para a sociedade em geral, contribuindo para uma melhor qualidade de vida e bem-estar subjetivo.

É importante ressaltar as limitações da pesquisa no que tange ao perfil buscado para os pais, tratando-se apenas de jovens adultos economicamente ativos. Da mesma forma, os filhos encontravam-se na faixa de 2 a 5 anos no momento das entrevistas, de modo que não participaram pais de crianças que já tivessem iniciado as atividades escolares. Ainda, pode ser entendida como uma oportunidade de novos estudos a ampliação do espaço demográfico desta pesquisa, aqui delimitado aos pais com residência na cidade de Porto Alegre, expandindo para outras regiões do Brasil.

Por fim, os resultados aqui encontrados poderão possibilitar novas pesquisas através da utilização das diretrizes de design identificadas, oportunizando não somente a criação de aplicativos mobile para facilitar a rotina dos pais, como auxiliando em questões referentes à educação e a criação das crianças. Novos dispositivos tecnológicos podem ser desenvolvidos, como pulseiras ou acessórios infantis que oportunizem a comunicação entre o pai e os filhos ao longo do dia, ou artefatos de tecnologia que auxiliem nas atividades da rotina da criança e nas práticas lúdicas e de lazer em família. 
O design, através da sua forma de enxergar a complexidade do mundo contemporâneo, oferece a habilidade de lidar com valores intangíveis, operando na ressignificação de sentido dos artefatos tecnológicos (Moraes, 2010). É através deste papel transformador que o design deve se apropriar destas necessidades emergentes, ocasionadas pelo avanço da tecnologia, proporcionando maior bem-estar para o pai e para a sua família.

\section{Referências}

ALLEN S.; DALY K. The effects of father involvement: an updated research summary of the evidence. Centre for Families, Work \& Well-Being, University of Guelph, 2007.

ALMEIDA, D. M.; WETHINGTON, E.; MCDONALD, D. A. Daily variation in paternal engagement and negative mood: implications of emotionally supportive and conflictual interactions. Journal of Marriage and Family, v. 63, p. 417-429, 2001.

BARCLAY, L.; LUPTON, D. The experiences of new fatherhood: a socio-cultural analysis. Journal of Advanced Nursing, v. 29, p. 1013-1020, 1999.

BARDIN, L. Análise de conteúdo. Lisboa: Edições 70, 2006.

BAUER, M.W.; GASKELL, G. Pesquisa qualitativa com texto, imagem e som: um manual prático. 3ed. Petrópolis: Vozes, 2004.

BROWN, T. Change by design: how design thinking transforms organization and inspires innovation. New York: Harper Collins, 2009.

CHAUDRON, S. Young children (0-8) and digital technology: a qualitative exploratory study across seven countries. Joint Research Centre, European Commission, 2015.

COVEY, S. R. Os sete hábitos das pessoas altamente eficazes. Rio de Janeiro: BestSeller, 2007.

CRESWELL, J. W. Investigação qualitativa e projeto de pesquisa: escolhendo entre cinco abordagens. Porto Alegre: Penso Editora, 2014.

CROUTER, A. C.; BUMPASS, M.; HEAD, M.; MCHALE, S. Implications of overwork and overload for the quality of men's relationships. Journal of Marriage and the Family, v. 63, p. 404-416, 2001.

DEMIR, E.; DESMET, P.; HEKKERT, P. Appraisal patterns of emotions in human-product interaction. International Journal of Design, v. 3, n. 2, p. 41-51, 2009.

DESMET, P. Designing emotions. Delft, The Netherlands. Tese de Doutorado. Delft University of Technology, 225 p., 2002.

DESMET, P. Framework of product emotion. In: S. POGGENPOHL (Ed.). IASDR: emerging trends in design research. Anais do IASDR: emerging trends in design research. Hong Kong, 2007.

DESMET, P. Product Emotion. In: P. Hekkert, \& H.N.J. Schifferstein (Eds.). Product Experience. Amsterdam: Elsevier, p. 379-397, 2008.

DESMET, P. M. A.; HEKKERT, P. Framework of product experience. International Journal of Design, 1(1), 57-66, 2007. 
DESMET, P. M. A.; POHLMEYER, A. E. Positive design: an introduction to design for subjective wellbeing. International Journal of Design, v. 7. n. 3, p. 5-19, 2013.

DIAS, P.; BRITO, R. Crianças ( 0 aos 8 anos) e tecnologias digitais: um estudo qualitativo exploratório. Relatório nacional (Portugal). Lisboa: Centro de Estudos de Comunicação e Cultura, 2016.

EGGEBEEN, J.D.; DEW, J.; KNOESTER, C. Fatherhood and men's lives at middle age. Journal of Family Issues, v. 31, p. 113-130, 2010.

FISHBACH, A.; ZHANG, Y. Together or apart: when goals and temptations complement versus compete. Journal of Personality and Social Psychology, v. 94, n. 4, 547-559, 2008.

FONTANELLA, B. J. B.; RICAS, J.; TURATO, E. R. Amostragem por saturação em pesquisas qualitativas em saúde: contribuições teóricas. Cadernos de Saúde Pública, v. 24, n. 1, p. 17-27, 2008.

FLICK, U. Introdução à pesquisa qualitativa. 3ed. Porto Alegre: 2009.

FREITAS, W. M. F.; SILVA, A. T. M. C.; COELHO, E. A. C.; GUEDES, R, N.; LUCENA, K. D. T.; COSTA, A. P. T. Paternidade: responsabilidade social do homem no papel de provedor. Revista de Saúde Pública, v. 43, n. 1, p. 85-90, 2009.

FRIJDA, N. H. The emotions. Cambridge: Cambridge University Press, 1986.

GENC, Z. Parents' perceptions about the mobile technology use of preschool aged children. ProcediaSocial and Behavioural Sciences, v. 146, p. 55-60, 2014.

GERGEN, K. J.; GERGEN, K. J. The challenge of absent presence. In: J. E. Katz \& J. E. Aakhus (Eds.), Perpetual contact: mobile communication, private talk, public performance (pp. 227-241). Cambridge, UK: Cambridge University Press. 2002.

JACKSON, S. Learning, digital media, and creative play in early childhood: spotlight on digital media and learning. Chicago, IL: MacArthur Foundation, 2011.

JORDAN, P. W. Pleasure with products: human factors for body, mind and soul. In: W. S. Green \& P. W. Jordan (Eds.), Human factors in product design: current practice and future trends. London: Taylor \& Francis, p. 206-217, 1999.

KANE, D.C.; GADSDEN, V.L.; ARMORER, K.R. The fathers and families core learnings: an update from the field. Philadelphia: National Center on Fathers and Families, Graduate School of Education, University of Pennsylvania, 1997.

KEENEY, J.; BOYDE, E. M.; SINHA, R.; WESTRING, A. F.; RYAN, A. M. From work-family to worklife: broadening our conceptualization and measurement. Journal of Vocational Behavior, v. 82, p. 221237, 2013.

KENNEDY, T.L.M.; SMITH, A.; WELLS, A. T.; WELLAM, B. Parents and spouses are using the internet and cell phones to create a "new connectedness" that builds on remote connections and shared internet experiences. Pew Internet and American Life Project, 2008.

LAZARUS, R. S. Emotion and adaptation. Oxford: Oxford University Press. 1991.

MANDELLI, R. R.; TONETTO, L. Design para empatia: brinquedos e brincadeiras como oportunidade para promover o desenvolvimento emocional. Pesquisas e Práticas Psicossociais v. 14, n. 1, p. 1-22, 2019. 
MCDANIEL, B. T.; COYNE, S. M.; HOLMES, E. K. New mothersand media use: associations between blogging, social network-ing, and maternal well-being. Maternal and Child Health Journal, v. 16, p. 1509-1517, 2012.

MCDANIEL, B. T. "Technoference": everyday intrusions and interruptions of technology in couple andfamily relationships. In: C. J. Bruess (Ed), Family communication in the age of digital and social media. NewYork: Peter Lang, 2015.

MILKIE, M. A.; MARYBETH, A.; MATTINGLY, J.; NOMAGUCHI, K. M..; BIANCHI, S. M.; ROBINSON, J. P. The time squeeze: parental statuses and feelings about time with their children. Journal of Marriage and Family, v. 66, p. 739-61, 2004.

MILKIE, M. A.; KENDIG, S. M.; NOMAGUCHI, K. M.; DENNY, K. E. Time with children, children's well-being, and work-family balance among employed parents. Journal of Marriage and Family, v. 72, p. 1329-1343, 2010.

NORMAN, D. Emotional design: why we love (or hate) everyday things. New York: Basic Books, 2004.

OLMSTEAD, C. Using technology to increase parent involvement in schools. TechTrends: Linking Research and Practice to Improve Learning, v. 57, n. 6, p. 28-37, 2013.

OULASVIRTA, A.; RATTENBURY, T.; MA, L.; RAITA, E. Habits make smartphone use more pervasive. Personal and Ubiquitous Computing, v. 16, n. 1, p. 105-114, 2012.

OZKARAMANLI, D; DESMET, P. I Knew I shouldn't, yet I did it again! Emotion-driven Design as a means to motivate subjective well-being. International Journal of Design, v. 6, n. 1, p. 27-39, 2012.

OZKARAMANLI, D.; DESMET, P.M.A.; ÖZCAN, E. Beyond resolving dilemmas: three design directions for addressing intrapersonal concern conflicts. Design Issues, v. 32, n. 3, p. 78-91, 2016.

OZKARAMANLI, D.; DESMET, P. M. A.; ÖZCAN, E. Is this a design-worthy dilemma? Identifying relevant and inspiring concern conflicts as input for user-centered design. Journal of Design Research, v. 15, n. 1, p. 17-42, 2017.

OZKARAMANLI, D.; ÖZCAN, E.; DESMET, P.M.A. Long-term goals or immediate desires? How to use self-control dilemmas to design for distant gains. The Design Journal, v. 20, n. 2, p. 219-238, 2017.

PADILLA-WALKER, L. M.; COYNE, S. M.; FRASER, A. M. Getting a highspeed family connection: associations between family media use and family connection. Family Relations, v. 61, p. 426-440, 2012.

RADESKY, J. S.; SCHUMACHER, J.; ZUCKERMAN, B. Mobile and interactive media use by young children: the good, the bad, and the unknown. Pediatrics, v. 135, p. 1-3, 2015.

SARACHO, O. Developmentally-appropriate technology and interactive media in early childhood education. In: K. Heider; M. Renck Jalongo (Eds.) Young children and families in the information age: educating the young child (Advances in theory and research, implications for practice). Dordrecht: Springer, 2015.

SILVA, A.C.; OLIVEIRA, L. H. Conciliando a realização pessoal, o trabalho e a família: um estudo com mulheres do interior do Rio Grande do Sul. Revista Psicologia em Foco, v. 6, n. 2, p. 1-19, 2014. 
SAWYER, S. M.; AZZOPARDI P. S.; WICKREMARATHNE, D.; PATTON, G. C. The age of adolescence. The Lancet Child \& Adolescent Health, v. 2, n. 3, p. 223-228. 2018.

TONETTO, L.M. A perspectiva cognitiva no design para emoção: análise de concerns em projetos para a experiência. Strategic Design Research Journal, v. 5, p. 1-17, 2012.

TONETTO, L.M.; COSTA, F.C.X. Design Emocional: conceitos, abordagens e perspectivas de pesquisa. Strategic Design Research Journal, v. 3, n. 4, p.132-140, 2011.

TONETTO, L.M.; PEREIRA, A.S.; KOLLER, S.H.; BRESSANE, K.; PIEROZAN, D. Designing toys and play activities for the development of social skills in the childhood. The Design Journal, v. 23, n. 2, p. 199$217,2020$.

TONETTO, L.M.; RENCK, P.; STEIN, L. Perspectivas metodológicas na pesquisa sobre o comportamento do consumidor. Psicologia: Ciência e Profissão, v. 34, p. 180-195, 2014

WELLMAN, B., SMITH, A., WELLS, A., KENNEDY, T. Networked families. Washington: Pew Research Center, Internet, Science \& Tech, 2008.

ZEVENBERGEN, R. LOGAN, H. Computer use in preschool children: rethinking practice as digital natives come to preschool. Australian Journal of Early Childhood, v. 33, p. 2-44, 2008. 